\title{
Sexual Misconduct: Are You Aware?
}

\author{
ANNE C. RUSS, PHD, LAT, ATC ${ }^{1}$; JAMIE L. MANSELL, PHD, LAT, ATC ${ }^{1}$; DANI M. MOFFIT, \\ PHD, LAT, ATC ${ }^{2}$ \\ ${ }^{1}$ Department of Health and Rehabilitation Sciences, College of Public Health, Temple University \\ ${ }^{2}$ Department of Human Performance and Sport Studies, Idaho State University
}

Correspondence: anne.russ@,temple.edu (Anne C. Russ)

\begin{abstract}
Sexual misconduct, a continum of unwanted acts and behaviors that ranges from discrimination to assault, is a growing concern in bealth care. There is often a power dynamic involved, with the perpetrator having greater positional power than the victim. Both health care providers and educators in health care programs need to be aware of sexual misconduct. This includes using consent when working with a patient and/ or student as well as being sensitive to how varying contextual factors impact how actions and conversations are received. Institutions of higher learning and professional health care programs have a responsibility to educate individuals on prevention and recognition of sexual misconduct, reporting sexual misconduct, and responding to sexual misconduct. As rules continue to change, there is a responsibility to educate and protect students and patients.
\end{abstract}

\section{Introduction}

An athlete pointed toward his groin and mouthed "come get this."

Athlete purposely skimmed my breast in the athletic training room.

Football players were running into my athletic training room naked and asking if I liked what I saw.

Anonymous athlete on a male team tweeted a sexual comment about the female atbletic training student working with them.

I was told that I would not get certain jobs due to the fact I was a woman.

All of the above are true stories of sexual misconduct that athletic trainers have experienced (AM Simmons, unpublished data). Sexual misconduct is a continuum of acts, including unwanted attention and non-consensual interactions, and can happen to anyone, regardless of their sex assigned at birth, gender identity, and/or gender expression. Typically, though not exclusively, it involves power dynamics, with a person in a position of power coercing a person with lesser influence. ${ }^{1}$ Within athletic training and other health care professions, this may involve a practitioner having power over their patient or a student working alongside them in a clinical fieldwork experience. Limited research evidence suggests that due to this dynamic, the individual may not interpret the action as sexual misconduct, but rather an unwanted action that they have to endure in their role. ${ }^{2}$ 
Sexual misconduct has the potential to negatively impact the victim's life. Limited research suggests that people who have experienced sexual misconduct often report changes in their emotional status, general health, sleeping habits, and may withdraw from school or quit their job. ${ }^{3,4}$ Some health care providers who have been survivors of sexual misconduct report diminished job satisfaction, leading to mistreatment of their patients. ${ }^{5}$ These consequences have large personal and community impacts. Therefore, it is vital for those working in public health and health care to be informed about sexual misconduct. In this article, we will describe the continuum of sexual misconduct and describe ways to protect ourselves, our patients, and our students.

\section{What is Sexual Misconduct?}

The Sexual Exploitation Continuum ${ }^{6}$ (Figure 1) was first described in 1997 as a way to visualize the relationship between sexual discrimination, harassment and abuse along the continuum of sexual violence. It consists of three overlapping stages: sex and gender discrimination, sex and gender harassment, and hazing/sexual abuse.

Figure 1. Sexual Misconduct Continuum*6

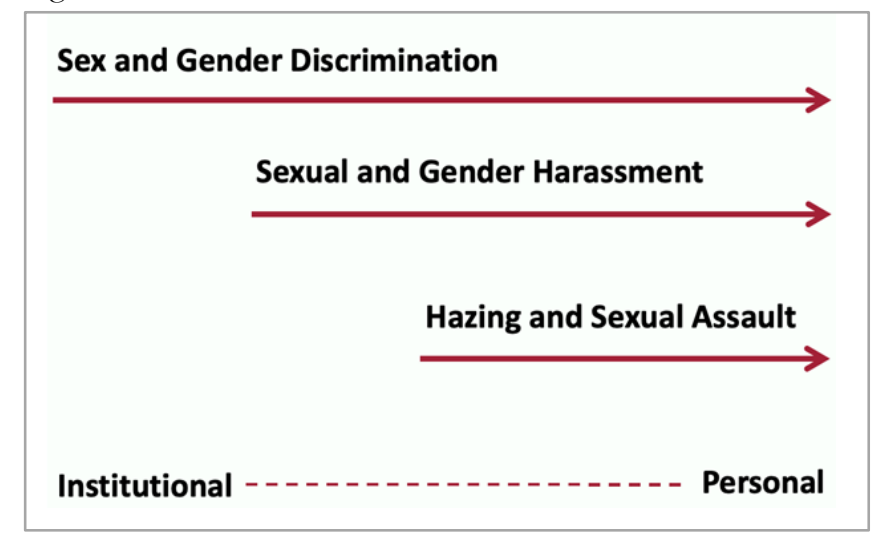

*Adapted from Brackenridge ${ }^{6}$

\section{Sex and Gender Discrimination}

Sex and Gender Discrimination is typically more institutionally driven and directed towards groups of people with similar characteristics. One example of this is when women are hired for executive positions in traditionally female-dominated professions, ${ }^{7}$ such as nursing or occupational therapy, but the same does not hold true in other professions. ${ }^{8}$ Sex and Gender Discrimination also encompasses wage disparities between genders. The adjusted gap in average starting salaries between male and female physicians has grown from $\$ 7,700$ in 1999 to $\$ 20,200$ in $2017 . .^{9}$ Other considerations include access to workplace facilities, such as a lack of gender-neutral restrooms or access to breastfeeding/pumping rooms for nursing mothers. While many of these actions are common, they are often difficult to prove in court. ${ }^{10}$

\section{Sex and Gender Harassment}

The middle span on the Sexual Exploitation Continuum is sexual and gender harassment, which can be both institutionally and personally driven. ${ }^{6}$ This category includes unwanted attention, hazing activities, and homophobia. Pervasive in health care, harassment has been demonstrated across several professions 
and genders. In a 12 -month period, $58 \%$ of female surgeons, ${ }^{11}$ and $28.1 \%$ of female and $5.6 \%$ of male EMS providers ${ }^{12}$ reported sexually harassing behaviors during their job. Almost half of transgender and gender nonbinary physicians report experiencing barriers based on their status when applying for jobs. ${ }^{13}$ Over the course of their careers, $61 \%$ of male and $76 \%$ of female physicians report being sexually harassed, ${ }^{14}$ and 2 out of 5 athletic trainers report being victims of sexual harassment (AM Simmons, unpublished data). While typically thought as only a female problem, this data reflects that sexual misconduct affects all genders.

\section{Hazing and Sexual Abuse}

The highest range on the Sexual Exploitation Continuum is Hazing and Sexual Abuse. This stage is the most personal. It is characterized by the appearance of the victim being groomed or coerced by a person in power. Actions that are identified as abuse include forced sexual activity, sexual assault, and indecent exposure. ${ }^{6}$ Some abuse includes quid pro quo, with the promise of reward in return for sexual favors. ${ }^{15}$ Within the past few years, there has been strong media attention on cases of sexual abuse in health care. Larry Nassar, a physician for USA gymnastics, ${ }^{16}$ was accused of assaulting over 250 gymnasts and pled guilty to charges of child pornography and sexual assault of minors. An Ohio State University physician has over 300 individuals alleging sexual abuse claims posthumously, with the University settling with some victims. ${ }^{17}$ Many of these cases are calculated, with perpetrators in positions of power, taking the same actions against multiple victims in lesser power positions over an extended period of time. Oftentimes, actions were, unreported, dismissed, or even, covered-up. ${ }^{6,16,17}$

\section{Gray Areas: How Society Views Sexual Misconduct}

The concept of the Sexual Exploitation Continuum is important, as many perpetrators may "groom" victims with more subtle acts, advancing along the continuum. Victims do not always recognize these initial acts as harassment or abuse until after they are entrapped. ${ }^{6}$ Bystanders and others tend to blame the victim because they do not see the harassment through the grooming lens, and often use the phrase "they were asking for it" when referring to the victim. ${ }^{6}$

The Sexual Exploitation Continuum is helpful to define the different categories under the umbrella; however, there are often "gray areas" and contextual factors to consider (Figure 2).

Figure 2. The Spectrum of Sexual Misconduct at Work*18

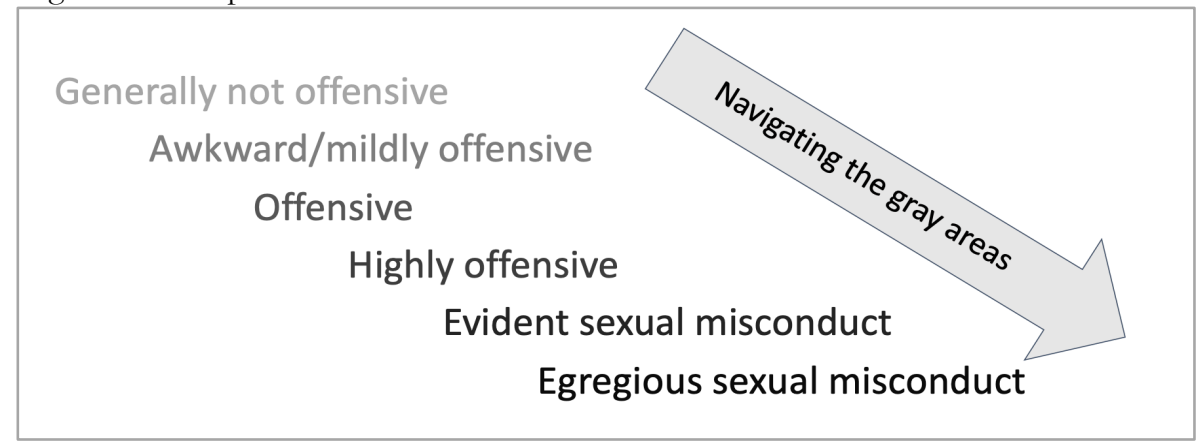

*Adapted from Kelly Reardon ${ }^{18}$ 
A person may be more or less likely to view an action as sexual misconduct for many situational or individual reasons. Some of these factors include the history of the people involved, the tone of delivery if a verbal encounter, and non-verbal actions or body language. ${ }^{18}$ For example, "you look nice today" said between two colleagues with a close friendship may be interpreted as a compliment; however, those same words spoken in a different tone or from a stranger or someone without that close friendship and/or accompanied by a suggestive look may be interpreted as harassment. It is important to remember that sexual misconduct includes unwanted attention, regardless of the intent of the action. The power dynamic, physical setting, tone of voice, conversational tenor, and relationship history all impact how the interaction is received. A seemingly innocuous question such as, "What are you doing this weekend?", could be perceived differently if chatting with a patient in an open patient area versus being asked behind closed doors. It also depends on who is taking the action. Calling someone by a pet name, such as "honey", is perceived as less threatening when it is done by peers compared to those in power roles. ${ }^{19}$ What makes this complicated is that there are many factors at play and most sexual misconduct guidelines address reporting cases, not preventing cases. ${ }^{20}$

\section{Sexual Misconduct in Health Care Education}

While the decades-long incidence of sexual misconduct in health care is alarming, it is important to note that it is also experienced by students in didactic and clinical education components. Students are often placed in vulnerable positions in the classroom and clinical settings. Within clinical lab classes, students act as mock patients and are routinely touched by peer classmates and instructors. While in their clinical or fieldwork placements, they gain exposure to their field by examining and rehabilitating patients, often in small rooms and using physical touch. Students graded by their preceptors and supervisors become vulnerable due to the power differential present. Eighty-three percent of athletic training students report being sexually harassed by a student-athlete, 36\% report harassment from a coach, and $25 \%$ said they were harassed by a certified athletic trainer. ${ }^{21}$ While in medical school, $73 \%$ of women and $22 \%$ of men reported at least one incidence of sexual harassment. ${ }^{22}$ Statistics from both are dated, but are indicative of a culture that is pervasive in required clinical rotations and not often studied. The \#MeToo movement has demonstrated just how often these situations occurred and were never verbalized by those who believed it was just part of the job. ${ }^{23}$

\section{How Can I Protect Myself, My Patients and Students?}

Health care providers have a responsibility to protect their patients, just as educators have a responsibility to protect their students. Clinicians need to abide by their profession's ethical standards and code of conduct. Whatever we can do to remain vigilant in our practice and education of students is imperative. Since there is a paucity of research that examines the effectiveness of sexual misconduct training, the authors have several recommendations for educators, health care providers, and students.

There needs to be transparency in all actions and an awareness of how actions are being perceived. When providing hands-on patient care, one should explain what is going to happen and ask for consent from the other party. For example, when a patient comes to a clinician for an ankle evaluation, the clinician should be explaining the evaluation process to the patient and asking for consent throughout the entire process.

The same holds true when educating students regarding hands-on skills, whether in a classroom, laboratory or clinical setting. The educator, be it an instructor or preceptor, needs to follow these same principles of explaining and asking for consent prior to demonstrations. As students are practicing the skills, they should be following the same approach, so they can utilize it with their own patients. 
Educators need to follow and abide by institutional policies.

\section{How can schools and programs protect students in clinical placements?}

In 2011, the Dear Colleagues Letter ${ }^{24}$ put forward by the Obama Administration's Department of Education, suggested that all institutions of higher education provide training for students on sexual harassment. This recommendation was imprecise and left it up to the individual schools to decide if, and how, to implement. While many schools have started this, one training may not be enough, and may not target the needs of health care and fieldwork. A single training session may be too broad and is meant as an overview for the students. ${ }^{25}$ By creating training sessions specific to fieldwork and health care, students may have more concrete examples of what sexual misconduct looks like in their settings. These trainings may be more beneficial if they are on-going and interactive.

Beyond training, schools can take steps to create more inclusive environments for students seeking help if they experience or observe sexual misconduct. Implicit bias, Safe Space, and Question, Persuade, Refer (QPR): Gatekeeper trainings can help students and faculty demonstrate empathy and validation that goes hand-in-hand when someone reports sexual misconduct. Furthermore, many health care professions have a code of ethics, which all professionals are expected to follow. Professional degree programs should ensure the curriculum includes education on the profession's code of ethics, as well as professional responsibility.

\section{Conclusion}

Health care providers and educators need to acknowledge that we are in a position of power over patients and students and must recognize our professional responsibility. Title IX of the Educational Amendments established commitment of equal access to education for males and females, and the Supreme Court recognizes that sexual misconduct can interfere with a student's education. In 2011, the Obama Administration provided Title IX guidelines for educational institutions on how to protect students by responding to claims of sexual harassment and assualt. ${ }^{24}$ In recent years, the Trump administration decided to dissolve previous Title IX rules, narrowing the definition of sexual harassment and better protecting those accused of sexual misconduct, with allowances for live hearings, crossexaminations, and providing evidence to both parties. ${ }^{26}$ Critics have said that this may make people less likely to come forward to seek the help and treatment they need, ${ }^{27}$ which can perpetuate the cycle and exacerbate the impact of abuse. Beyond these new guidelines, we have a responsibility to follow our professional and institutional code of ethics, as well as code of conduct, and do what is right by our patients and students.

\section{Disclosures and Conflicts of Interest}

The authors declare that there is no conflict of interest. 


\section{References}

1. Sand TS, Fasting K, Chroni S, Knorre N. Coaching behavior: any consequence for the prevalence of sexual harassment? Int J Sport Sci Coach. 2011;6(2):229-240.

2. Shingles RR, Smith Y. Perceptions of sexual harassment in athletic training. Athl Train Educ J. 2008;3(3):102-107.

3. Recupero PR, Heru AM, Price M, Alves J. Sexual harassment in medical education: Liability and protection. Acad Med. 2004;79(9):817-824.

4. Hill C, Kearl H. Crossing the Line: Sexual Harassment at School. AAUW Educational Foundation: Washington, DC. 2011.

5. Nagata-Kobayashi S, Maeno T, Yoshizu M, Shimbo T. Universal problems during residency: abuse and harassment. Med Educ. 2009;43:628-636.

6. Brackenridge C. 'He owned me basically...' Women's experience of sexual abuse in sport. Int Rev Sociol Sport.1997;32(2):15-130.

7. Bureau of Labor Statistics, US Department of Labor [Internet]. 2016 August. [Cited 2020 March 27]. Available from https://www.bls.gov/opub/ted/2016/39-percent-of-managers-in-2015-werewomen.htm

8. Acosta RV, Carpenter LJ. A longitudinal, national study: thirty-five year update-1977-2012. Women in Intercollegiate Sport. 2012 January [Cited 2020 March 27]. Available from http://www.acostacarpenter.org/2014\%20Status $\% 20$ of $\% 20$ Women $\% 20 \mathrm{in} \% 20$ Intercollegiate $\% 20 \mathrm{~S}$ port $\% 20-37 \% 20$ Year $\% 20$ Update $\% 20-\% 201977-2014 \% 20$.pdf

9. LoSasso AT, Armstrong D, Forte G, Gerber SE. Differences in starting pay for male and female physicians persist; Explanations for the gender gap remain elusive. Health Affair. 2020;39(2):256-263

10. Maxmen A. Why it's hard to prove gender discrimination in science. Nature. 2018 May. [Cited 2020 March 8]. Available from https://www.nature.com/articles/d41586-018-05109-w

11. Nayar A, Scarlet S, Strassle PD, Ollilia DW, Erdahl LM, McGuire KP, Gallagher KK. A national survey of sexual harassment among surgeons. Academic Surgical Congress Abstracts Archive. 2019. 85.06.

12. Yoo J, Kim JH, Yoon J, Kim SS. Sexual harassment and its relationship with depressive symptoms: A nationwide study of Korean EMS providers. Am J Ind Med. 2018;62:74-79.

13. Dimant OE, Cook TE, Greene RE, Radix AE. Experiences of transgender and gender non binary medical students and physicians. Transgend Health. 2019;4(1):209-216

14. Jenner S, Djermester P, Prugl J, Kurmeyer C, Oertelt-Prigione S. Prevalence of sexual harassment in academic medicine. JAMA Intern Med. 2019;179(1):108-111.

15. Equal Employment Opportunity Commission [Internet]. Washington DC. c. 199. [cited 2020 March 8]. Available from: https://www.eeoc.gov/policy/docs/sexualfavor.html

16. Urie M. Sexual exploitation in the sport industry: an abuse of power. Washington, DC: National Ctr on Sexual Exploitation. 2018 Feb. [Cited 2018 April 27]. Available from: https://endsexualexploitation. org/articles/sexual-exploitation-sports-industry-abuse-power/.

17. Frellick M. Former Ohio State team doctor sexually abused at least 177, report shows. Medscape. 2019 May. [Cited 2019 May 29]. Available from: https://www.medscape.com/viewarticle/913342?src=wnl_edit_tpal\&uac $=218336$ DK\&impID $=19$ $71757 \&$ faf $=1$

18. Kelley Reardon K. It's Not Always Clear What Constitutes Sexual Harassment. Use this Tool to Navigate the Gray Areas. Harvard Business Review. 2018 June. [Cited 2019 June 1]. Available from: https://hbr.org/2018/06/its-not-always-clear-what-constitutes-sexual-harassment-use-this-tool-tonavigate-the-gray-areas

19. Moffit DM, Mansell JL, Russ AC, Wu J. Perceptions of sexual misconduct and the overall role of peer athletic training students, athletes, preceptors, and coaches. Journal of Allied Health. 2020;49(1):e21-25. 
20. Christman T. Statement on Handling Sexual Abuse. National Athletic Trainers' Association. 2018 February 5. [Cited 2020 March 27]. Available from https://www.nata.org/blog/toddchristman/statement-handling-abuse.

21. Hauth JM, Vanic KA, Menon S. The perceived incidence of sexual harassment among student athletic trainers in NATA district one and two. J Athl Training, 2000;35(S), S-75.

22. Komaromy M, Bindman A, Haber R, Sande M. Sexual harassment in medical training. The New Eng J Med. 1993;328(5):322-326

23. Hogshead-Makar, N. How to Stop Sexual Abuse in Sports. Athletic Business. 2018 January. [Cited 2018 April 15]. Available from https://www.athleticbusiness.com/athlete-safety/how-to-stopsexual-abuse-in-sports.html

24. United States Department of Education Office of Civil Rights. Dear Colleague Letter. Washington, D. C. U. S. Government Printing Office. 2011.

25. Mansell JM, Moffit DM, Russ AC, Thorpe JN. Sexual harassment training and reporting in students. Athl Train Educ J. 2017;12(1):3-9.

26. Nondiscrimination on the Basis of Sex in Education Programs or Activities Receiving Federal Financial Assistance, 34 CFR Part 106 (2018).

27. Meckler L. Betsy DeVos Poised to Issue Sweeping Rules Governing Campus Sexual Assault. Washington Post. 2019 November. [Cited 2020 March 8]. Available from: https://www.washingtonpost.com/local/education/betsy-devos-poised-to-issue-sweeping-rulesgoverning-campus-sexual-assault/2019/11/25/f9c21656-0f90-11ea-b0fc-62cc38411ebb_story.html

\section{Statement of Contributions}

All authors contributed to the conceptualization, writing, reviewing and editing of the article.

\section{About the Authors}

Drs. Mansell, Moffit, and Russ are all "Temple Made" and have worked with each other since 2006. The authors have been collaborators in the field of sexual harassment research in athletic training since 2013. These efforts resulted in several state, regional, national, and even international presentations as well as peer-reviewed publications. The group won the 2017 Athletic Training Education Journal Outstanding Original Research Manuscript for their article "Sexual harassment training and reporting in athletic training students". Currently, the authors are developing a training program for clinicians and professional-level students.

Dr. Russ is an Assistant Professor in the Department of Health and Rehabilitation Science at Temple University. Dr. Mansell is an Associate Professor and Program Director for the Athletic Training master's and doctoral programs at Temple University. Dr. Moffit is an Associate Professor and Program Director for the Athletic Training master's program at Idaho State University. 